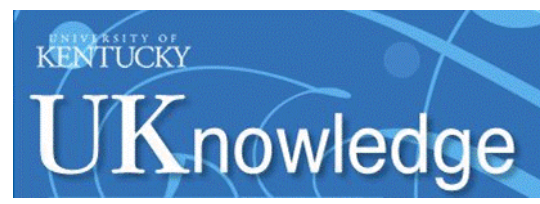

University of Kentucky

UKnowledge

$1-2015$

\title{
Interfacial Bond between Reinforcing Fibers and Calcium Sulfoaluminate Cements: Fiber Pullout Characteristics
}

\author{
Robert B. Jewell \\ University of Kentucky, bob.jewell@uky.edu \\ Kamyar C. Mahboub \\ University of Kentucky, kc.mahboub@uky.edu \\ Thomas L. Robl \\ University of Kentucky, tom.robl@uky.edu \\ Arne C. Bathke \\ University of Kentucky, arne@uky.edu
}

Follow this and additional works at: https://uknowledge.uky.edu/ce_facpub

Part of the Civil Engineering Commons, and the Construction Engineering and Management Commons

Right click to open a feedback form in a new tab to let us know how this document benefits you.

\section{Repository Citation}

Jewell, Robert B.; Mahboub, Kamyar C.; Robl, Thomas L.; and Bathke, Arne C., "Interfacial Bond between Reinforcing Fibers and Calcium Sulfoaluminate Cements: Fiber Pullout Characteristics" (2015). Civil Engineering Faculty Publications. 5.

https://uknowledge.uky.edu/ce_facpub/5

This Article is brought to you for free and open access by the Civil Engineering at UKnowledge. It has been accepted for inclusion in Civil Engineering Faculty Publications by an authorized administrator of UKnowledge. For more information, please contact UKnowledge@lsv.uky.edu. 


\section{Interfacial Bond between Reinforcing Fibers and Calcium Sulfoaluminate Cements: Fiber Pullout Characteristics}

Digital Object Identifier (DOI)

http://dx.doi.org/10.14359/51687234

\section{Notes/Citation Information}

Published in ACl Materials Journal, v. 112, no. 1, p. 39-48.

Copyright $($ C 2015, American Concrete Institute.

The copyright holder has granted the permission for posting the article here. 


\title{
Interfacial Bond between Reinforcing Fibers and Calcium Sulfoaluminate Cements: Fiber Pullout Characteristics
}

\author{
by Robert B. Jewell, Kamyar C. Mahboub, Thomas L. Robl, and Arne C. Bathke
}

The results of an experimental investigation on the influence of the interfacial bond of reinforcing fibers embedded in a calcium sulfoaluminate matrix on the fiber-pullout peak load and energy consumption are presented. Bonding at the fiber-matrix interface plays an important role in controlling the mechanical performance of cementitious composites - in particular, composites formed from sulfate-based systems (calcium sulfoaluminate [CSA] cements), as opposed to the silicate systems found in portland cement. Various types of fibers were selected, including polyvinyl alcohol (PVA), polypropylene, and copper-coated steel. The fibers were embedded in three different matrixes: two sulfate-based cements including one commercially available CSA cement and a CSA fabricated from coal-combustion by-products. The third matrix was a silicatebased ordinary portland cement (OPC). In this study, the results of the single-fiber pullout test were coupled with scanning electron microscopy (SEM) to examine the interfacial bond between the fiber and CSA matrix for evidence of debonding and possible hydration reaction products.

Keywords: CSA cement; fibers; interfacial bond; low-energy cement; pullout test.

\section{INTRODUCTION}

The primary reason for the addition of fibers to cementitious matrixes is to delay and contain cracking. ${ }^{1,2}$ While it is generally believed that the inclusion of fibers enhances the precracking behavior of cement composites by increasing its cracking strength, the effect of fiber addition becomes evident only after cracking. ${ }^{1-3}$ Fibers bridge the cracked parts of the matrix, thus delaying sudden global failure of the composite. ${ }^{3}$ Therefore, in the post-cracking stage, the fiber behavior is governed by the interfacial bond stress response as being subjected to pullout loads. ${ }^{1}$ The bond between fiber and matrix is important - if fibers have a weak bond with the matrix, they can slip out at low loads and do not contribute to preventing the propagation of cracks. However, if the bond is too strong, then the fibers may rupture before they can contribute to the post-crack strength of the matrix material.

Fiber-reinforced composites (FRCs) resist tensile forces through a composite action, whereby part of the tensile force is resisted by the matrix, while the balance is taken by the fibers. ${ }^{1}$ The transmission of forces between the fiber and the matrix is achieved through a bond defined as the shearing stress at the interface between the fiber and the surrounding matrix. ${ }^{1}$ The fiber contribution to increasing the toughness (total energy absorbed with a unit $\mathrm{mJ}$ ) of the composite is primarily dictated by the mechanisms of fiber pullout. ${ }^{1,4}$ Fiber pullout tests are often used to study the fiber-matrix bond behavior in fiber-reinforced cement composites. This test simulates the fiber bridging-pullout mechanism during the fracture process of FRC. ${ }^{5}$ In relating pullout test results with the fiber-matrix bond characteristics, numerous studies have been completed to demonstrate the reliability of the data. ${ }^{1,6-11}$

Composites made with brittle fibers, such as steel, and brittle matrixes - that is, calcium sulfoaluminate (CSA) cement - can exhibit high fracture toughness when failure occurs preferentially along the interface before fibers fracture. Most of the important toughening mechanisms are a direct result of the interface-related shear failure, which gives rise to an improved energy absorption capability with a sustained crack growth stability through crack surface bridging and crack tip blunting. ${ }^{12}$ The prevalent type of cracking depends on the properties of the interface relative to the fiber and matrix. ${ }^{13}$ According to Kim and Mai, ${ }^{13}$ when a crack approaches an isolated fiber, the following failure mechanisms may be expected to take place: 1) fiber-matrix interface debonding; 2) post-debonding friction; 3) fiber fracture; 4) stress redistribution; and 5) fiber pullout.

The cement-fiber interfacial bond results from some combination of mechanical interlocking of cement hydration products with the fiber surface, and chemical reaction between fiber and cement paste within the interstitial transition zone. ${ }^{4,13-15}$ In FRC materials, the principal factor governing load transfer from the matrix to the fiber is shear strength of the interfacial bond between the two components. Fractured specimens of fiber-reinforced concrete shows that failure takes place primarily due to fiber pullout or debonding. Generally, fiber pullout, rather than rupture, confers a larger ductility to the FRCs. ${ }^{3,12}$ Unlike plain concrete, a fiber-reinforced concrete specimen does not break immediately after initiation of the first crack, thereby increasing the work of fracture, or toughness. Within the cracked section, the matrix does not resist any tension and the fibers carry the entire load applied to the composite. With an increasing load on the composite, fibers will tend to transfer additional stress to the matrix through bond stresses. If these bond stresses do not exceed the bond strength, then there may be additional cracking in the matrix. This process of multiple cracking will continue until either the fibers fail or accumulated local debonding will lead to fiber pullout. ${ }^{16,17}$

ACI Materials Journal, V. 112, No. 1, January-February 2015

MS No. M-2012-313.R3, doi: 10.14359/51687234, received April 22, 2014, and reviewed under Institute publication policies. Copyright (C) 2015, American Concrete Institute. All rights reserved, including the making of copies unless permission is obtained from the copyright proprietors. Pertinent discussion including author's closure, if any, will be published ten months from this journal's date if the discussion is received within four months of the paper's print publication. 
Table 1-Properties of reinforcing fibers (data from product technical datasheet)

\begin{tabular}{|c|c|c|c|c|c|c|}
\hline Fiber type & $\begin{array}{l}\text { Tensile strength, } \\
\mathrm{MPa}(\mathrm{ksi})\end{array}$ & $\begin{array}{l}\text { Young's modulus, } \\
\mathrm{GPa}(\mathrm{ksi})\end{array}$ & Fiber elongation, $\%$ & $\begin{array}{l}\text { Density, } \mathrm{g} / \mathrm{cm}^{3} \\
\left(\mathrm{lb} / \mathrm{in}^{3}{ }^{3}\right)\end{array}$ & $\begin{array}{l}\text { Fiber surface area, } \mathrm{mm}^{2}\left(\text { in. }^{2}\right) \\
\quad(6 \mathrm{~mm}[0.24 \text { in.] length })\end{array}$ & $\begin{array}{l}\text { Fiber length, } \\
\text { mm (in.) }\end{array}$ \\
\hline Polyvinyl alcohol & $1200(180)$ & $30(4351)$ & 7 & $1.30(0.05)$ & $1.89(0.003)$ & $12(0.47)$ \\
\hline Steel & $1200(174)$ & $120(17400)$ & 5 & $7.80(0.28)$ & $2.85(0.004)$ & $13(0.51)$ \\
\hline
\end{tabular}

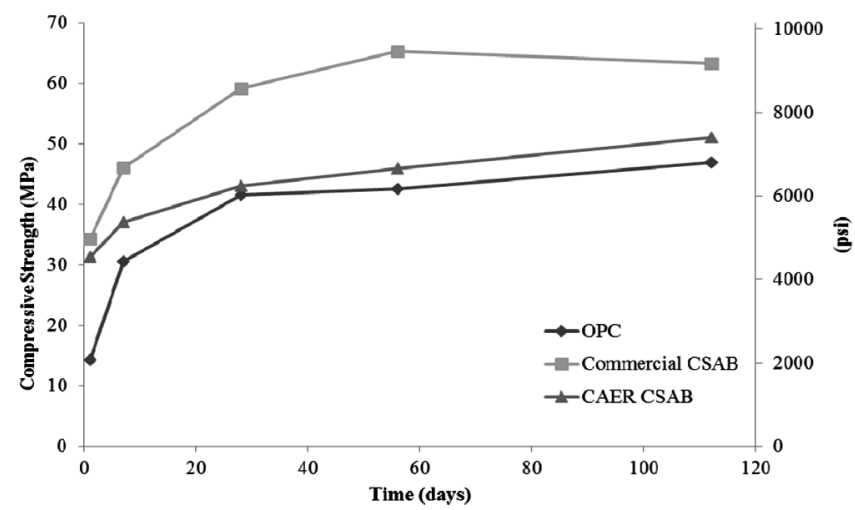

Fig. 1-Compressive strength of mortar cubes.

The principal phases of CSA clinker are $4 \mathrm{CaO} \cdot 3 \mathrm{Al}_{2} \mathrm{O}_{3} \cdot \mathrm{SO}_{3}$ $\left(\mathrm{C}_{4} \mathrm{~A}_{3} \mathrm{~S}\right)$, also called Klein's compound or yeelimite; $\mathrm{Ca}_{2} \mathrm{SiO}_{4}\left(\mathrm{C}_{2} \mathrm{~S}\right)$, or belite; and $\mathrm{C}_{4} \mathrm{AF}$, or brownmillerite. ${ }^{18}$ Other phases such as calcium aluminates (for example, $\mathrm{C}_{12} \mathrm{~A}_{7}$ or $\mathrm{C}_{11} \mathrm{~A}_{7} \mathrm{CaF}_{2}$ ) are sometimes present. Unlike portland cement, which gains its strength from the hydration of calcium silicates alite $\left(\mathrm{C}_{3} \mathrm{~S}\right)$ and belite $\left(\mathrm{C}_{2} \mathrm{~S}\right)$, CSA cement gains strength from the hydration of Klein's compound with calcium sulfate (such as gypsum [CŚ $\left.\mathrm{CH}_{2}\right]$ or anhydrite [CŚ]) to form ettringite via these reactions ${ }^{19}$

$$
\begin{gathered}
\mathrm{C}_{4} \mathrm{~A}_{3} \mathrm{~S}+2 \mathrm{CSSH}_{2}+34 \mathrm{H} \rightarrow \mathrm{C}_{6} \mathrm{AS}_{3} \mathrm{H}_{32}+2 \mathrm{AH}_{3} \\
\mathrm{C}_{4} \mathrm{~A}_{3} \mathrm{~S}+2 \mathrm{CS}+38 \mathrm{H} \rightarrow \mathrm{C}_{6} \mathrm{AS}_{3} \mathrm{H}_{32}+2 \mathrm{AH}_{3}
\end{gathered}
$$

These reactions are relatively fast, and are nearly complete within 1 month. When the sulfate anion is depleted, ettringite $\left(\mathrm{C}_{6} \mathrm{AS}_{3} \mathrm{H}_{32}\right.$ [AFt phase]) is converted to monosulfate $\left(\mathrm{C}_{4} \mathrm{AS} \mathrm{S}_{12}\right.$ [AFm phase or "mono" phase]), which reduces the strength of the cement. ${ }^{20}$

\section{RESEARCH SIGNIFICANCE}

Calcium sulfoaluminate (CSA) cements present considerable environmental advantages compared to portland cement because of lower production energy, lower $\mathrm{CO}_{2}$ emissions, and the use of coal combustion wastes as raw materials. Although there is sufficient information on the performance of CSA systems, there is a lack of research that characterizes the bond properties of fibers in these cements. Therefore, this paper presents the development of CSA-fiber interfacial bond characteristics in the context of material design under the guidance of micromechanical tools. Specifically, this study illustrates how the fiber/matrix interface is enhanced by the use of sulfate-based cements when compared to silicatebased systems, providing some guidance in properly selecting a combination of fiber and matrix that provides efficient bond strength.

\section{EXPERIMENTAL PROGRAM}

The single-fiber pullout test was conducted to investigate the peak pullout load and corresponding pullout energy. The major parameter investigated is the effect of sulfate-based hydration products' ability to bond to various fiber types over silicate-based hydration products.

\section{Materials}

Three types of cements were investigated: ordinary portland cement (OPC); a commercially available calcium sulfoaluminate (CSA) cement; and a calcium sulfoaluminate belite (CSAB) cement fabricated from coal combustion by-products (CCBs). The study took place at the University of Kentucky Center for Applied Energy Research (CAER), referred to in this study as CAER CSAB. Following ASTM C109/C109M, the strength profiles of the cements used in this study are shown in Fig. 1. ${ }^{21}$ Polypropylene (PP) fiber, polyvinyl alcohol (PVA), and Type 1 copper-coated steel fibers were used in this study (Table 1).

\section{Fabrication of CSAB cement from CCBs}

Mixtures of fluidized-bed combustion (FBC) spent-bed material, bauxite, and limestone, were interground for clinkering. The fluidized-bed combustion by-product was of particular interest as a primary component for the fabrication of CSA cement due to the high lime content, and presence of alumina and calcium sulfate. The FBC material was added as a raw component in cement fabrication to reduce the amount of limestone necessary to create CSA cement. Reducing the limestone raw feed reduces associated $\mathrm{CO}_{2}$ emissions and produces a softer clinker that requires less energy to grind to cement fineness. The raw material was clinkered at $1250^{\circ} \mathrm{C}\left(2282^{\circ} \mathrm{F}\right)$, as determined from a burnability study, and included compositions in the stability fields of Klein's compound and belite. Mineral composition of the clinker product was determined by X-ray diffraction.

Cement formulations were calculated using Bogue equations that were modified for phases in CSAB clinker: this formulation is termed "CAER CSAB." ${ }^{22,23}$ The phases assumed to be present were Klein's compound, belite, ferrite $\left(\mathrm{C}_{4} \mathrm{AF}\right)$, calcium sulfate, and a small amount of lime $(<0.5 \%)$. The FBC material is a potential source of $\mathrm{CaO}$ and $\mathrm{SO}_{3}$ and, thus, was used as a partial substitute for gypsum and limestone in the laboratory CSAB raw materials (Table 2). The clinker was ball-milled with gypsum to make the final cement product. The gypsum is used to "activate" the Klein's compound to form additional ettringite during hydration. 
Table 2-CSAB cement and raw-feed materials composition from XRF analysis

\begin{tabular}{c|c|c|c|c|c|c|c|c}
\hline \multirow{2}{*}{ Cement } & \multicolumn{7}{c}{ Chemical composite, \% by wt } \\
\cline { 2 - 21 } & $\mathrm{SiO}_{2}$ & $\mathrm{Al}_{2} \mathrm{O}_{3}$ & $\mathrm{Fe}_{2} \mathrm{O}_{3}$ & $\mathrm{CaO}$ & $\mathrm{MgO}$ & $\mathrm{Na}_{2} \mathrm{O}$ & $\mathrm{K}_{2} \mathrm{O}$ & $\mathrm{SO}_{3}$ \\
\hline OPC & 20.5 & 5.4 & 2.6 & 63.9 & 2.1 & 0.61 & 0.21 & 3.0 \\
\hline Commercial CSAB & 5.89 & 20.48 & 2.53 & 42.29 & 0.78 & 0.1 & 0.15 & 25.71 \\
\hline CSAB \#4 (CAER CSAB) & 8.21 & 24.30 & 2.59 & 40.02 & 1.32 & 0.14 & 0.62 & 22.30 \\
\hline FBC spent bed & 12.77 & 5.25 & 3.15 & 48.23 & 2.47 & 0.05 & 0.36 & 27.83 \\
\hline Bauxite & 10.61 & 78.75 & 5.25 & 0.28 & 0.18 & 0.01 & 0.03 & 1.53 \\
\hline FGD gypsum & 4.54 & 1.09 & 0.60 & 40.15 & 0.37 & $<0.01$ & 0.06 & 53.67 \\
\hline Limestone & 7.41 & 2.76 & 0.77 & 81.62 & 3.31 & 0.04 & 0.61 & 0.82 \\
\hline
\end{tabular}

\section{Single-fiber pullout test setup}

The pullout tests were conducted on a universal testing machine. A $2 \mathrm{kN}$ (450 lbf) load cell was used to measure the pullout load of the fibers with a displacement rate of $0.02 \mathrm{~mm} / \mathrm{s}(0.0008 \mathrm{in} . / \mathrm{s})$; displacement was measured as the crosshead movement. Fiber-free length was kept at a maximum of $1 \mathrm{~mm}(0.04 \mathrm{in}$.) to reduce the effects of fiber elongation. Fibers were embedded $6 \mathrm{~mm}(0.24$ in.) into a paste plug, which was held in place with a screw-type grip and secured in the $2 \mathrm{kN}$ (450 lbf) load cell. The fiber-free end was glued to a plastic-anchor plate and secured in the testing grip.

\section{Preparation of test specimens: fiber pullout test}

Test specimens were embedded in a paste plug (watercement ratio $[w / c]=0.45)$ with an $8 \mathrm{~mm}(0.31$ in.) diameter and $25 \mathrm{~mm}(0.98 \mathrm{in}$.) length. The shortest fiber was $12 \mathrm{~mm}$ (0.47 in.) in length; therefore, a depth of $6 \mathrm{~mm}(0.24 \mathrm{in}$.) was selected to maximize the available fiber-matrix bond surface to allow for quantitative comparison. Fiber characterization and properties are listed in Table 1. A depth gauge ensured fibers were embedded to $6 \mathrm{~mm}(0.24 \mathrm{in}$.) and perpendicularly aligned to the mold surface. Specimens were removed from molds and placed in a temperature- and humiditycontrolled environment and tested at 1, 7, 21, 28, and 56 days. Common to all fiber pullout tests is a certain amount of data scatter in the experimental results; therefore, five specimens were prepared for each test. Data scatter is attributed to the presence of naturally occurring random fiber flaws and the lack of uniformity in the surface characteristics along the length of each fiber. The data were statistically analyzed using a three-way analysis of variance (ANOVA) (cement type, fiber type, and days of curing). Additionally, the nonparametric rank-based ANOVA-type test proposed by Brunner et al. (1997) was used to confirm the results from the parametric ANOVA. ${ }^{24}$ The nonparametric test does not assume normality or homoscedastic errors. Therefore, its agreement with the parametric ANOVA can be interpreted as a confirmation that the latter's assumptions were not grossly violated. Also, the nonparametric ANOVA-type test is invariant under monotone transformations of the data, meaning in particular that it does not matter whether the original data or log-transformed data are analyzed.

\section{EXPERIMENTAL RESULTS AND DISCUSSION Single-fiber pullout test}

Tests were performed using single fibers to compare the pullout (direct tension) resistance and energies consumed during debonding and pullout of PVA, PP, and steel fibers. Results of the single-fiber pullout test indicated increased peak stress and energy consumption for CSA-based cements than results obtained with an OPC (Table 3). Load-position curves were very different between the three fiber types, as seen in Fig 2. The three-way ANOVA indicated the peakstress test data varied statistically $(\alpha=0.05)$ according to cement type $(P<0.01)$, fiber type $(P<0.01)$ and days of curing $(P<0.01)$, but that the type of cement and days of curing interaction did not vary statistically. The statistical analysis demonstrated a significant interaction between the fiber type and days of curing as well as between cement type and fiber type. Additionally, for the pullout-energy consumption the three-way ANOVA indicated test data varied statistically according to fiber type $(P<0.01)$ and days of curing $(P<0.01)$, but that the type of cement interaction did not show a statistically significant effect. The statistical analysis demonstrated a significant interaction between cement type and fiber type, with less significance between fiber type and days of curing. The steel fibers showed an overall higher peak load and energy consumption than the PP and PVA fibers $(P<0.01)$ in all three cement types.

PVA fiber-Breaking of the chemical bond is evident in the first significant load drop, in a typical single PVA-fiber pullout curve. It is hypothesized that the second increase in load with fiber pullout results from a slip hardening effect; this behavior is achieved through multiple cracking of the reinforced matrix. ${ }^{11,25}$ However, as the matrix continues to hydrate and chemically bond to the fiber surface, fiber failure is experienced more often and is seen as a truncation in the load curve. This type of failure occurs when the fibermatrix bond strength is greater than the tensile load capacity of the fiber; thus, the fiber ruptures in the fiber-free zone or debonded region of the fiber.

The use of PVA fibers has caused the mechanism of failure to change. The strong bond between the hydrophilic fiber and matrix has caused the failure site to move from the fiber surface to the more porous matrix region, creating multiple cracks. ${ }^{26,27}$ The porous region is most likely more brittle by comparison with the ductile interfacial layer with steel fibers. ${ }^{27}$ Another possibility is the shear load will focus on 
Table 3-Peak load, N, and energy consumption values, mJ

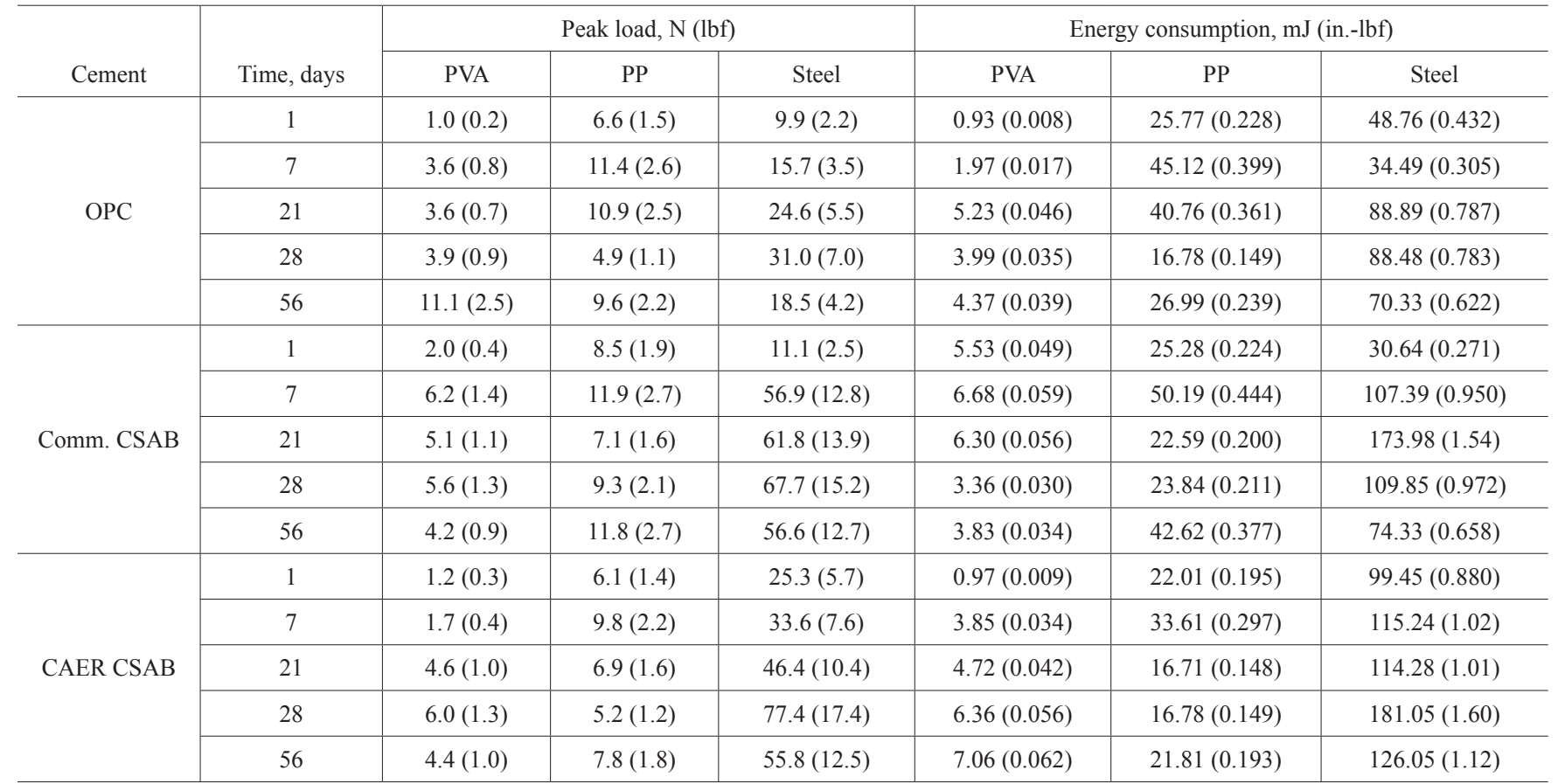
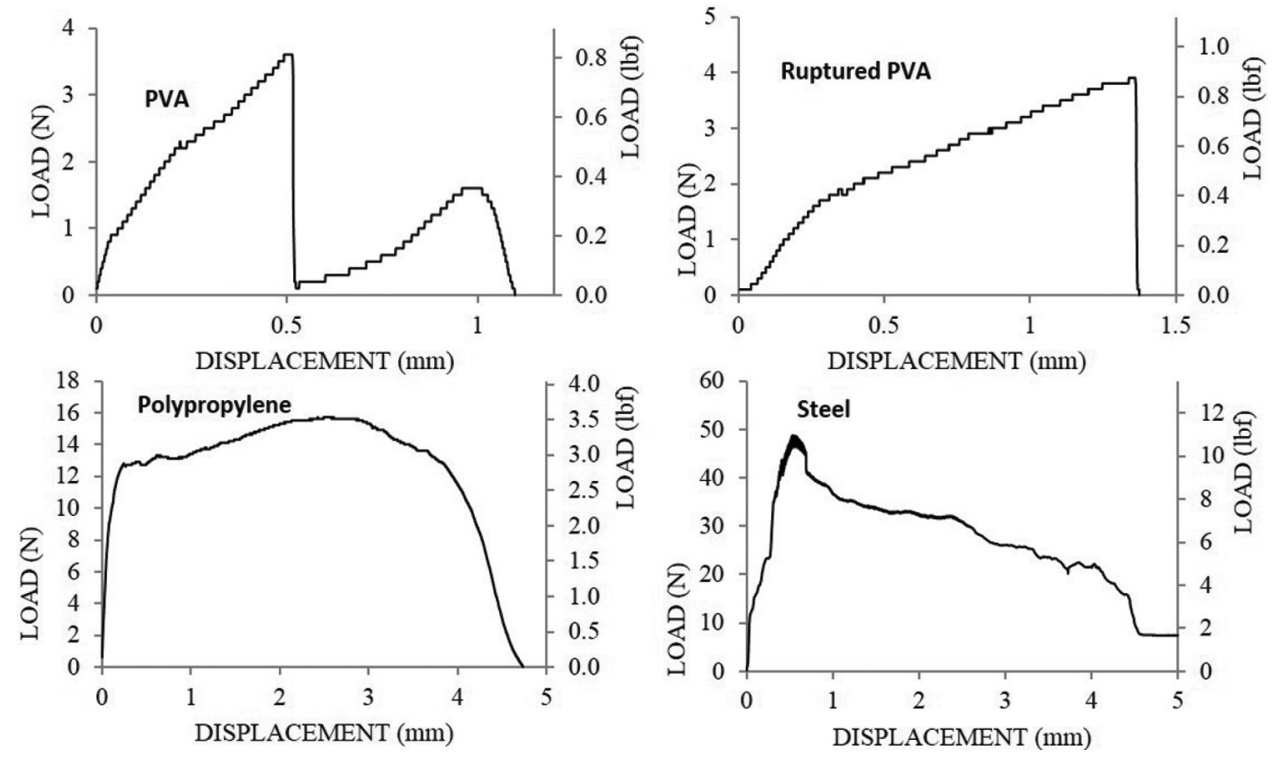

Fig. 2-Typical load-displacement curves for each fiber type.

the fiber itself, causing the fiber to rupture. Fiber surfaces were observed with a scanning electron microscope (SEM) to determine mechanical-bond characteristics that can be related to the data collected from the fiber pullout test.

PP fiber-A typical single PP-fiber pullout curve shows a broad curve with a large area below the curve, demonstrating the PP fiber's ability to increase the toughness of the composite (Fig. 2). PP fibers do not chemically bond to the surrounding matrix - they are hydrophobic and nonpolar; therefore the fiber separates from the matrix in an adhesive (no matrix phase residue on the fiber) manner. ${ }^{28,29}$ The surface morphology of PP fibers allow for surface irregularities ideal for matrix bonding as well as the potential for increased frictional loading during fiber pullout, due to the valley-and-ridge structure on the fiber surface (Fig. 3).

Copper-coated steel fiber-A typical single steel fiber pullout curve displays high peak loads relative to PVA and PP fibers, along with a shallow-sloping curve, indicative of slip hardening, and high energy consumption (Fig. 2). The steel fibers are coated with copper for corrosion resistance as stated by the manufacturer's product specifications. A scanning electron microscope (SEM) analysis of the fiber surface after a pullout test revealed the copper coating provided a preferential bonding surface for hydration products (Fig. 4). High peak loads with the steel fibers are attributed to the copper coating and surface roughness. ${ }^{11,30}$ Hydration products likely formed a complex with copper in the surface (as well as copper ions in solution) to form a strong bond. ${ }^{27}$ This bond allowed the interfacial layer of the matrix to remain bonded to the fiber during pullout. 

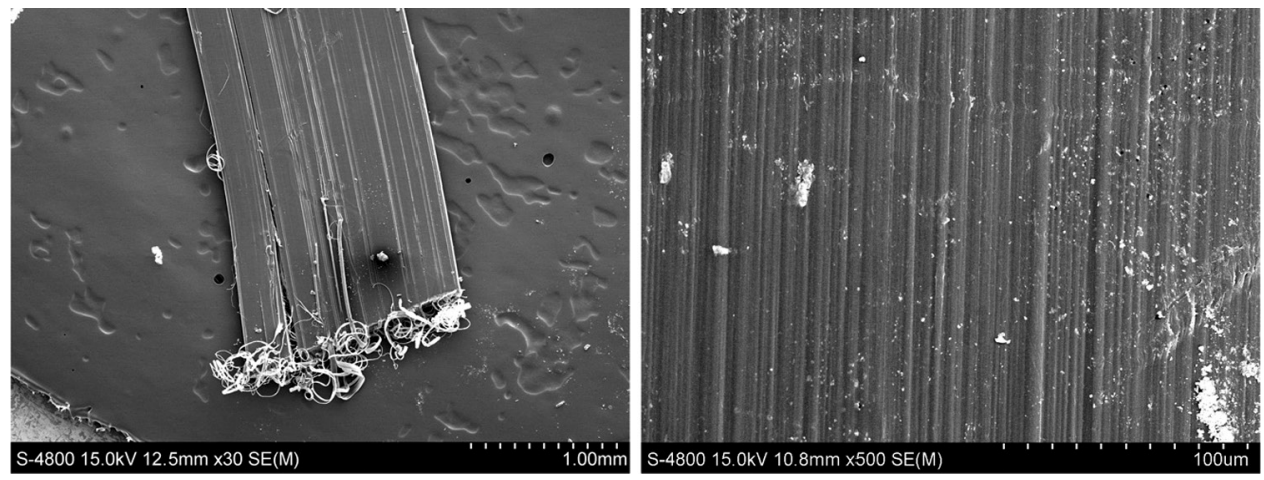

Fig. 3-Polypropylene fiber after the pullout test (left); and surface of fiber with valley-and-ridge structure (right).

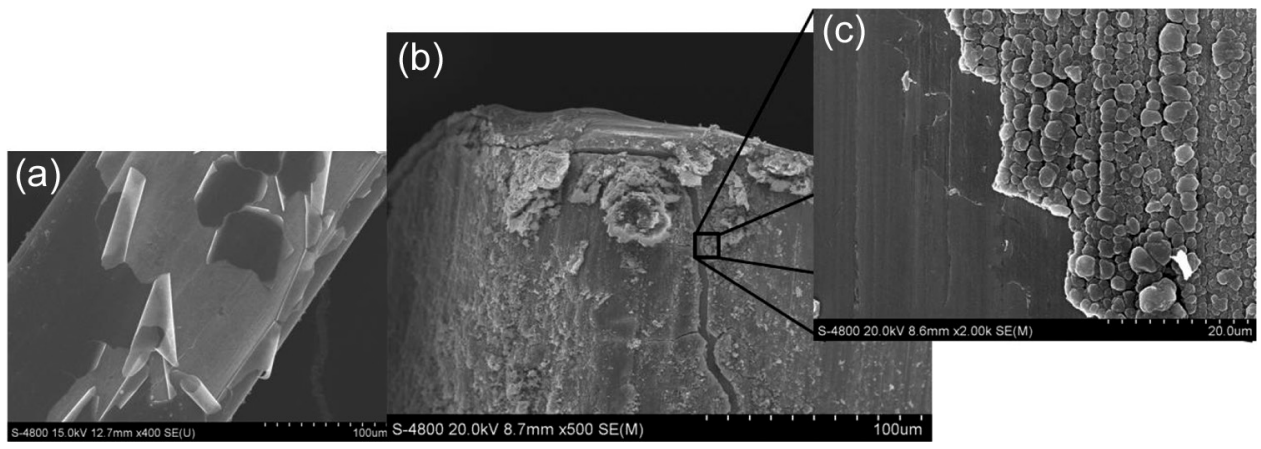

Fig. 4-SEM images of copper-coated steel fiber: (a) copper coating peeled from fiber surface; (b) fiber end with crack in copper coating; and (c) zoomed image of crack with defined boundary between copper coating and steel surface.

\section{Peak load analysis}

Ordinary portland cement-The steel fibers demonstrated the highest overall bonding strength from 7 to 56 days of curing-31.0 N (7.0 lbf) - represented by the peak-load data in Fig. 5. However, the PP fibers exhibited greater bond strength after 1 day of curing $(6.6 \mathrm{~N}[1.5 \mathrm{lbf}])$. As the OPC matrix continued to gain strength it also increased in stiffness; therefore, the fiber that exhibits a similar stiffness would yield higher peak load. Similar to steel fibers, PVA fibers also have a high modulus of elasticity and show resistance to stretching. The PVA fibers achieved a maximum peak load of $11.1 \mathrm{~N}(2.5 \mathrm{lbf})$ at 56 days of curing. After 21 days of curing, the fiber rupture rate increased, as expected, with increasing stiffness of the matrix and fiber-matrix bond. This is a similar trend exhibited by the CSAB cements, which will be discussed in the following sections. The SEM images in Fig. 6 indicate the fibers were completely pulled from the matrix since there was no indication of failure along the fiber tip. There are particles attached to the fibers, which indicate the presence of bonding between fiber and matrix, as compared to the surface of the fiber before they were embedded in the matrix.

Calcium silicate hydrate (C-S-H) grains form a fibrous, or fibrillar, morphology within the hardened paste. ${ }^{31,32}$ These grains help form the interfacial bond between the fiber and surrounding matrix. However, they are thin and do not form an extremely dense structure, as seen within an ettringitebased matrix. The PVA fiber in Fig. 6(a) demonstrates the preference for bonding to this type of fiber. PVA fibers easily form a complex cluster with available metal hydroxide ions

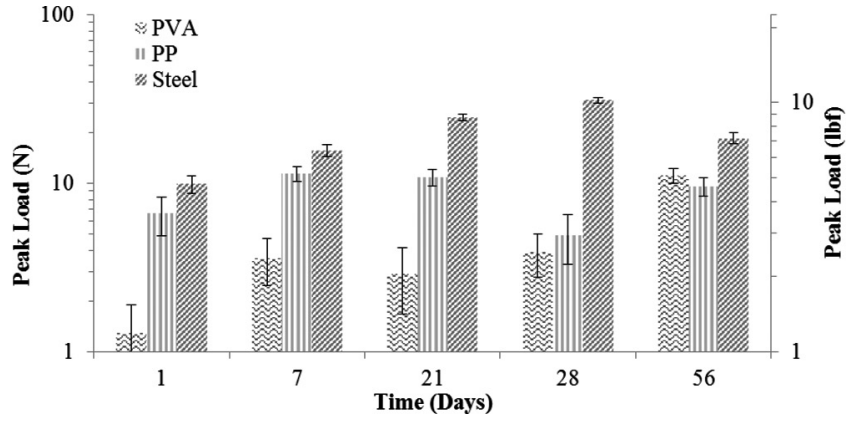

Fig. 5-Peak load development of PVA, PP, and steel fibers embedded in an OPC matrix. Standard error of the mean are indicated for each column.

and, in some cases, bond to the matrix through the interfacial transition zone by a layer of calcium hydroxide $\left(\mathrm{Ca}(\mathrm{OH})_{2}\right){ }^{33}$

Commercial CSAB cement-The main hydration product of CSA is ettringite, which precipitates together with amorphous $\mathrm{Al}(\mathrm{OH})_{3}$ until the available calcium sulfate is consumed after 1 to 2 days of hydration. Afterward, monosulfate is formed. However, the microstructure of CSA cement is denser than portland cement even after 16 hours of hydration. The dense structure and acicular nature of ettringite crystals aids the increased bond strength development. Whereas, OPC hydration products form layers of C-S-H gel and calcium hydroxide crystals on the fiber surface, a minor amount of a phase near the composition of ettringite forms during early hydration stages. ${ }^{23}$

The steel fibers have the highest overall bonding strength from 1 to 56 days of curing, as represented by the peak loads (Fig. 7). The PP fibers exhibit an increasing peak load from 

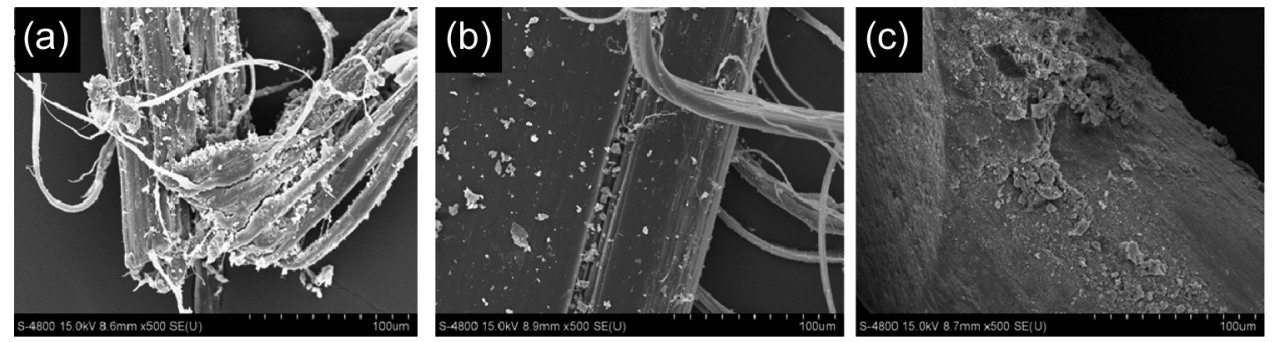

Fig. 6-SEM images of fibers pulled from the OPC matrix (500× magnification): (a) PVA; (b) PP; and (c) steel.

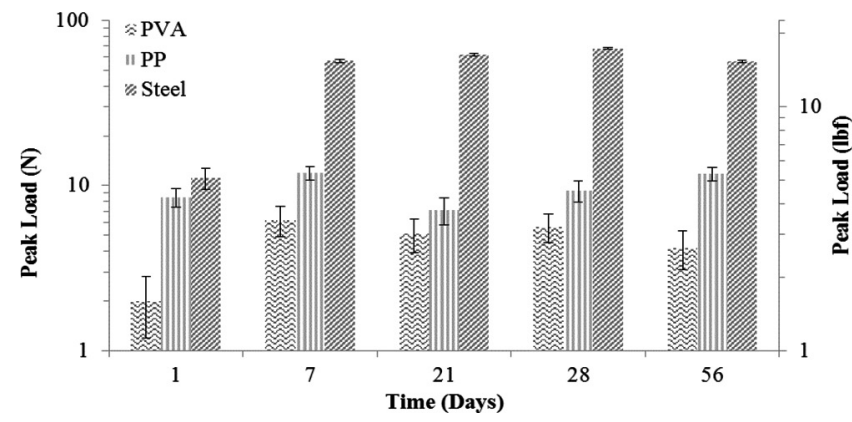

Fig. 7-Peak load development of PVA, PP, and steel fibers in commercial CSAB matrix.

3 hours to 56 days with a maximum load of $12 \mathrm{~N}$ (2.7 lbf) attained at 7 and 28 days of curing. PVA fibers achieved a maximum peak load of $6.2 \mathrm{~N}(1.4 \mathrm{lbf})$ at 7 days of curing. One reason for the lower peak loads with PVA fibers is from the crystallization of hydrated phases at nucleation sites on the fiber surface. ${ }^{34-36}$ The associated stronger bond moves the failure mode from the cement matrix into the fiber itself, resulting in rupture. Table 3 shows a decrease in pullout strength and toughness after 28 days of curing. This is attributed to the hydration mechanics of CSA cement in which the matrix has increased in density and strength to a point that will not permit dispersion of pullout forces throughout the matrix. Therefore, the fiber-matrix interface is the point of failure as the interface bond stress is exceeded by the pullout load. Long-term pullout behavior of fibers in CSA cements should be evaluated for strength-loss trends.

The SEM images in Fig. 8 provide a qualitative comparison of the fiber-matrix bond that occurs during hydration of the cement matrix. The PVA fiber demonstrates some surface deformation due to the interfacial bonding with the CSA matrix; the PP fiber shows less deformation than the OPC and CAER CSAB cement with an increased percentage of the surface coated with hydrated-matrix phases; the steel fiber shows large areas of bonding with the CSA matrix. In Fig. 8(c), the copper coating and bare-steel fiber boundary is shown; the copper coating in the lower half of the image is completely covered with hydrated-matrix phases.

CAER CSAB cement-The CAER CSAB cement is rich in Klein's compound, which in the presence of flue-gas desulfurization (FGD), gypsum hydrates rapidly to form ettringite. The CAER CSAB cement differs from commercially available CSA cement in that the ettringite crystals formed are longer and more slender, allowing for a tighter-interwoven network of crystals. This explains the increased bonding strengths seen in Fig. 9 as compared to the commercial CSAB cement in Fig. 7. The steel fibers exhibited higher peak loads as compared to the PP and PVA fibers. As previously mentioned, the increased pullout load may be attributed to the influence of the copper coating on the bond between steel fibers and cement matrix.

The SEM images in Fig. 10 demonstrate the increased fiber/matrix bond. The PVA fiber shows a high level of deformity when compared to its original form; sections of fiber have been pulled from the original structure, providing evidence of a strong bond between the fiber and surrounding matrix. The PP fiber shows a minor degree of deformity with voids and impressions filled with hydrated-cement phases; the steel fiber was covered by greater than $90 \%$ of matrix material bonded to the surface, or copper layer.

\section{Energy consumption analysis}

Energy consumption corresponding to the single-fiber pullout test refers to energy absorbed in the debonding process, which corresponds to the area under the loaddisplacement curve. $^{3}$ The energy consumption was determined with the universal testing machine machine operating software.

Ordinary portland cement-The copper-coated steel fibers obtained the highest overall energy consumption from 1 to 56 days of curing, with a maximum of $88 \mathrm{~mJ}$ (0.78 in.-lbf) at 21 and 28 days, as seen in Fig. 11. The PP fibers exhibited the highest energy consumption $-45.12 \mathrm{~mJ}$ (0.399 in.-lbf) at 7 days of curing. PVA fibers achieved a maximum energy consumption of $5.23 \mathrm{~mJ}$ (0.046 in.-lbf) at 21 days. The early-age ( 1 to 7 days) pullout tests yielded the best results with the softer PP fiber, in which the bond between the fiber and matrix was sufficiently strong enough to transfer the excess energy into the matrix. However, as the matrix continued to gain strength at 21 to 56 days of curing, the harder steel fibers were able to sustain the increased load for the entire fiber debonding process. After 21 days of curing, the fibers with a higher modulus of elasticity have a tendency to exhibit higher energy consumption.

Strands of PP fiber that appear to have peeled away from the main fiber body highly influence the large energy consumption exhibited by this type of fiber. In addition to the fiber-matrix bond, which appears minimal when compared to the matrix remnants bonded to the PVA and steel fibers, as the strands of PP are peeled away, they add to the energy consumption by enhancing frictional stresses during loading. The plastic nature of the PP fiber prevents catastrophic failure from occurring; alternatively, a broad stress-strain curve is produced. 

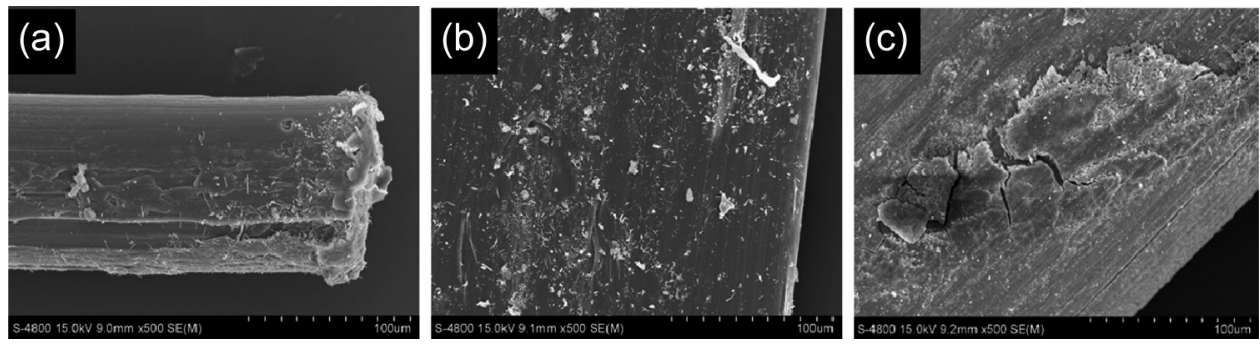

Fig. 8-SEM images of fibers pulled from the commercial CSAB matrix (500× magnification): (a) PVA; (b) PP; and (c) steel.

Commercial CSAB cement-The steel fibers obtained the highest overall energy consumption from 1 to 56 days of curing with a maximum of $173.98 \mathrm{~mJ}(1.54 \mathrm{in}$.-lbf) attained at 21 days (Fig. 12). The PVA fibers achieved a maximum energy consumption of $6.68 \mathrm{~mJ}$ ( 0.059 in.-lbf) after 7 days of curing. PP fibers attained a maximum energy consumption of $50.19 \mathrm{~mJ}$ (0.444 in.-lbf) after 7 days of curing. The decrease in energy consumption after 1 and 7 days of curing, for the PP fibers, may be attributed to a decrease in ductility with increasing hydration of Klein's compound to form ettringite, thereby forming an extremely dense matrix structure.

CAER CSAB cement-Similar to the commercial CSAB cement, the steel fibers exhibited the highest overall energy consumption from 1 to 56 days of curing with the CAER CSAB cement, with a maximum of $181.05 \mathrm{~mJ}$ (1.60 in.-lbf) attained at 28 days (Fig. 13). The PP fiber had a decreasing trend with time, correlating to a decrease in peak load. This may be attributed to an abundance of Klein's compound in the CAER CSAB cement, which will hydrate to form a larger volume of ettringite than the commercial CSAB cement.

Fibers with a high Young's modulus showed an overall increase in energy consumption for each of the pullout test days, including the PVA fiber. Though results were not as high as those attained with steel fibers, the PVA fiber reached a maximum energy of $3.85 \mathrm{~mJ}$ (0.034 in.-lbf) at 7 days of curing and sustained an energy consumption of approximately $7 \mathrm{~mJ}$ ( 0.062 in.-lbf) out to 56 days of curing. The leveling-off of maximum energy after 7 days for PVA fibers is directly associated with an increased percentage of fibers that ruptured during pullout.

\section{STATISTICAL ANALYSIS}

A statistical analysis was performed to determine any significance of the effects measured for the following experimental responses ${ }^{37}$ : the peak load corresponding to the maximum load supported by the fiber at the point before debonding, and the total energy consumption during the pullout process that corresponds to the region below the load-displacement curve. Based on the Box-Cox transformation technique, the data were $\log$ transformed. ${ }^{38}$ This reduced variance heterogeneity and made the data more symmetric, thus justifying the use of ANOVA inference methods on the transformed data.

Consistent with the Box-Cox log transformation, the summaries of peak load and energy consumption visualized in Fig. 5, 7, 9, 11, 12, and 13 are displayed on a logarithmic scale. Specifically, for the transformed data, mean plus/minus standard error of the mean were calculated

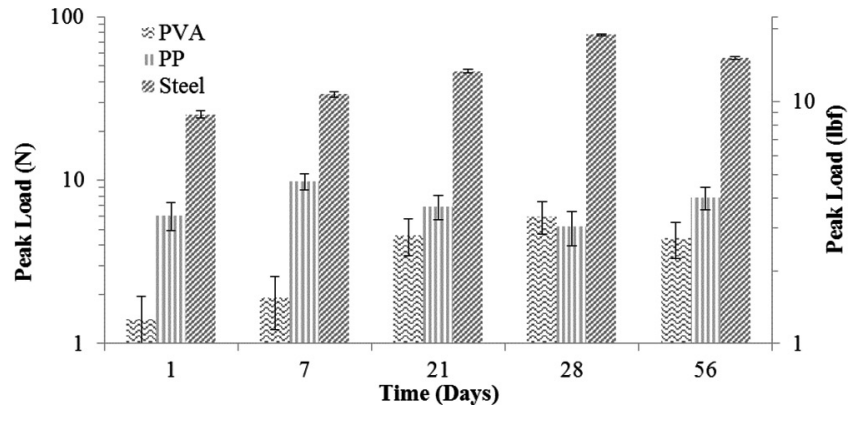

Fig. 9-Peak load development of PVA, PP, and steel fibers in CAER CSAB cement.

and transformed back to the original scale. Thus, the original magnitudes can be seen directly from the figures, but at the same time, it is possible to validate the appropriateness of the statistical inference, which was based on the transformed data.

\section{Peak load}

Table 3 displays the transformed mean loads obtained for each peak load for each of the 45 studied configurations. Table 4 gives the results of the ANOVA of the peak load data. From the table, it can be concluded that the cement, fiber, cement-fiber interaction, day and fiber-day interaction have been shown to have a statistically significant effect.

\section{Pullout energy consumption}

Table 3 displays the mean energy consumption during the pullout process for each of the configurations studies, and Table 5 gives the results of the ANOVA for the energy consumption. From the table, it can be concluded that the fiber, day, cement-fiber interaction, and fiber-day interaction variable have been shown to have a statistically significant effect.

\section{Synthesis of statistical analysis}

To summarize the significant effects for peak load, the cement type, fiber type, days of curing, and the interaction between cement and fiber type were highly significant. For energy consumption, the fiber type, days of curing, interaction between cement and fiber type, and the interaction between fiber type and days of curing were highly significant. The fiber type and days of curing always play an important role when evaluating behavior of the fiber with respect to all variables. The interaction between cement and fiber also plays an important role when evaluating the peak load and energy consumption. 

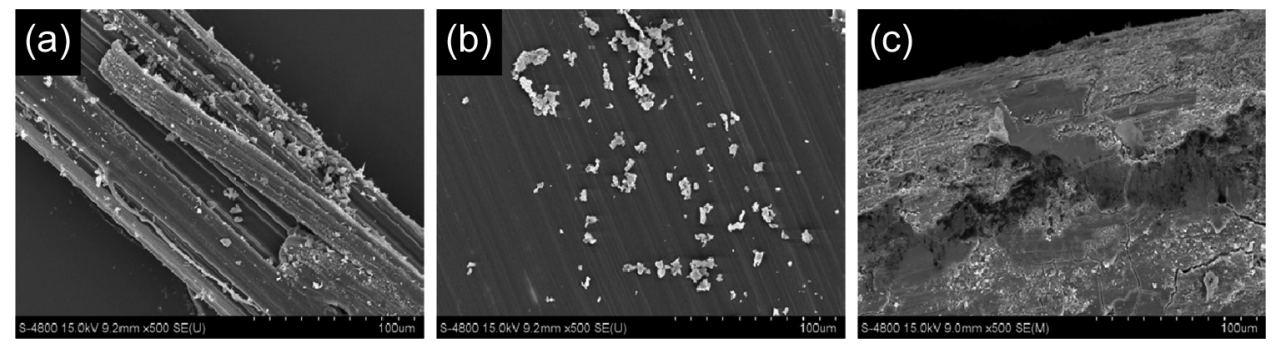

Fig. 10-SEM images of fibers pulled from CAER CSAB matrix (500× magnification): (a) PVA; (b) PP; and (c) steel.

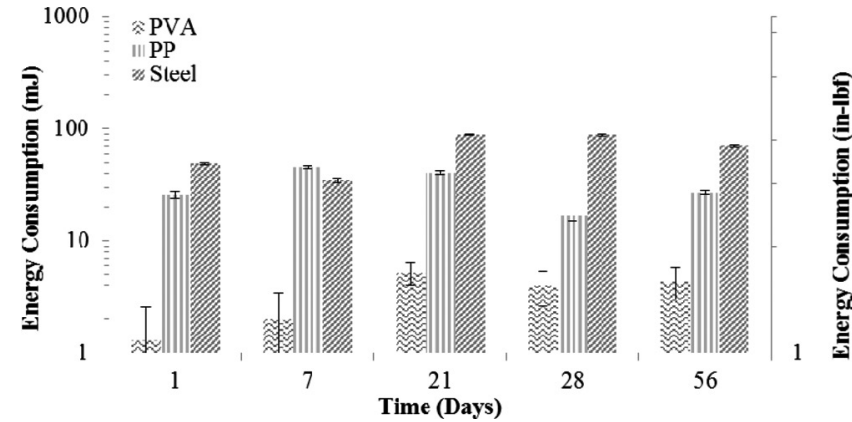

Fig. 11-Energy consumption development of PVA, PP, and steel fibers in OPC matrix.

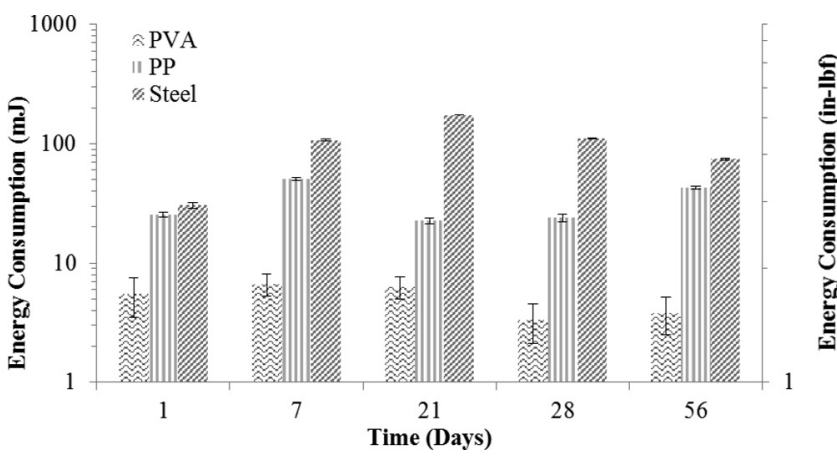

Fig. 12-Energy consumption development of PVA, PP, and steel fibers in commercial CSAB cement.

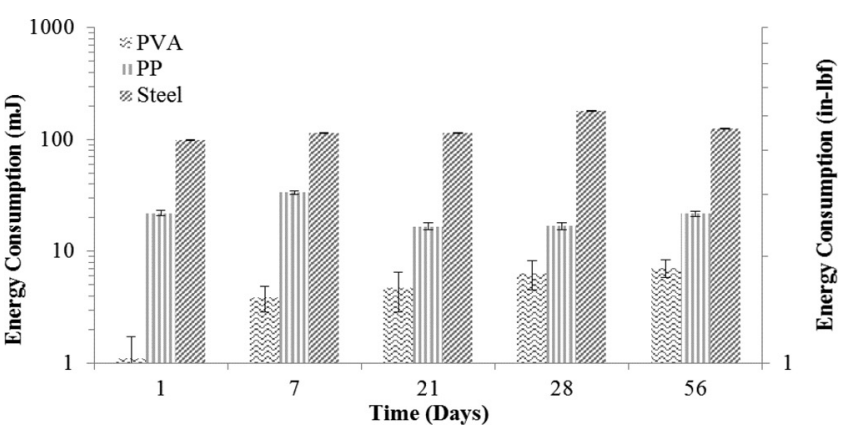

Fig. 13-Energy consumption development of PVA, PP, and steel fibers in CAER CSAB cement.

In comparing the significant variables between peak load and energy consumption, the cement played a key role in the peak load, which contributes to the significance of the cement-fiber interaction. The type of cement and cementfiber interaction played a key role in influencing the peak load analysis of the pullout test. The type of cement was not significant for the energy consumption; instead, the type of
Table 4-Analysis of variance on peak load

\begin{tabular}{c|c|c|c|c|c}
\hline Source & DF & $\begin{array}{c}\text { Type III } \\
\text { SS }\end{array}$ & $\begin{array}{c}\text { Mean } \\
\text { square }\end{array}$ & $F$ value & $\operatorname{Pr}>F$ \\
\hline Cement & 2 & 8.805 & 4.402 & 16.96 & $<.0001$ \\
\hline Fiber & 2 & 200.921 & 100.461 & 386.98 & $<.0001$ \\
\hline Cement-fiber & 4 & 7.644 & 1.911 & 7.36 & $<.0001$ \\
\hline Day & 4 & 23.386 & 5.847 & 22.52 & $<.0001$ \\
\hline Cement-day & 8 & 2.398 & 0.300 & 1.15 & 0.3292 \\
\hline Fiber-day & 8 & 12.609 & 1.576 & 6.07 & $<.0001$ \\
\hline Cement-fiber-day & 16 & 6.514 & 0.407 & 1.57 & 0.0814 \\
\hline
\end{tabular}

Table 5-Analysis of variance on energy consumption

\begin{tabular}{c|c|c|c|c|c}
\hline Source & DF & $\begin{array}{c}\text { Type III } \\
\text { SS }\end{array}$ & $\begin{array}{c}\text { Mean } \\
\text { square }\end{array}$ & $F$ value & $\operatorname{Pr}>F$ \\
\hline Cement & 2 & 4.099 & 2.050 & 3.50 & 0.0321 \\
\hline Fiber & 2 & 380.025 & 190.012 & 324.88 & $<.0001$ \\
\hline Cement-fiber & 4 & 8.109 & 2.027 & 3.47 & 0.0094 \\
\hline Day & 4 & 12.631 & 3.158 & 5.40 & 0.0004 \\
\hline Cement-day & 8 & 5.230 & 0.654 & 1.12 & 0.3533 \\
\hline Fiber-day & 8 & 12.684 & 1.586 & 2,71 & 0.0077 \\
\hline Cement-fiber-day & 16 & 14.810 & 0.926 & 1.58 & 0.0773 \\
\hline
\end{tabular}

fiber, days of curing, cement-fiber interaction, and fiber-day interaction played key roles in the pullout test. Fiber type was instrumental in sustaining toughness of the composite beyond the peak load of the pullout test. However, the fiber type that achieved the largest toughness was dependent on the right type of cement interaction.

\section{CONCLUSIONS}

The bonding characteristics of three fiber types and three different types of cement were examined. The single-fiber pullout test was used to quantify peak load and energy consumption. SEM analysis provided a qualitative comparison of the physical bonding characteristics for the fibers and matrix. As evident from this study, the ability to transfer interfacial stress from fiber to matrix is an important factor in bond strength. The more rigid-dense ettringite crystal structure yielded higher peak loads and larger energy consumption. Thin-fibrous C-S-H structures of the OPC matrix provided good bonding properties, which equated to large maximum peak loads. However, unable to resist debondingshear stresses, the thin C-S-H structure resulted in a fiber- 
matrix bond with small energy consumption. Pullout test results indicated the following:

1. Peak load and pullout-energy consumption differed significantly according to the fiber type, days of curing, and the interaction between fiber type and type of cement. The steel fibers showed higher peak load and energy consumption than the PP and PVA fibers.

2. High Young's modulus fibers achieved larger failure loads and energy consumption within a CSA-matrix throughout the curing regime. However, this result is only true in an OPC matrix after 7 days of curing.

3. Low-modulus fibers - that is, $\mathrm{PP}$ - are best suited to resist pullout forces in an OPC system at early ages of curing ( $<7$ days). This is attributed to the soft physical nature of the fiber, which is susceptible to deformation from delamination that in turn increases the frictional-shear resistance to pullout loads.

4. As evidenced from the pullout test, PVA fibers have a significantly lower strain capacity than the PP and steel fibers. Despite complete debonding, the decreased strain capacity is attributed to a high-strength chemical bond to the matrix with failure occurring near the fiber tip, close to the onset of shear-crack propagation.

A statistical analysis of peak load and energy consumption data was performed with the ANOVA test. Results indicated: 1) the importance of cement type, fiber type, and curing time on the peak load data obtained from the pullout test; 2) the interaction between cement and fiber type was highly significant, indicating performance will either improve or diminish based on the combination of these two variables; 3) cement type was not highly significant for energy consumption as compared to the significance of fiber type and days of curing; and 4) energy consumption was greatly influenced by the cement-fiber interaction. This was demonstrated by comparing the pullout test data between OPC and CSAB cement with fibers of varying elastic moduli.

In summary, the CAER CSAB cement, fabricated from CCBs, demonstrated optimum bonding characteristics with both steel and PVA fibers, where "optimum" is with regards to maximum peak load and energy consumption. However, PP fibers demonstrated optimum bonding within the commercial CSAB cement. Cements that produce rapid-high early strengths, such as CSA cements, are most compatible with fibers that exhibit a high modulus of elasticity. The known performance characteristics of reinforcing fibers in an OPC system do not reflect the performance of the same fibers in a CSA cement system. This is supported by the results of the ANOVA, indicating the cement-fiber interaction is highly significant for both peak load and energy consumption.

\section{AUTHOR BIOS}

Robert B. Jewell is a Research Scientist at the University of Kentucky Center for Applied Energy Research, Lexington, KY. He received his BS and MS in geological sciences from the University of Kentucky. He is a PhD candidate in the Department of Civil Engineering at the University of Kentucky.

ACI member Kamyar C. Mahboub is an Associate Dean of Engineering and the Lawson Professor of Civil Engineering at the University of Kentucky. He received his BSCE from The University of Texas at Austin, Austin, TX, and his MSCE and PhD from Texas A\&M University, College Station, TX. He is a member of ACI Committee 522, Pervious Concrete.
Thomas L. Robl is an Associate Director at the University of Kentucky Center for Applied Energy Research, a member of the University of Kentucky Graduate Faculty, and is a Director of the American Coal Council. He received a PhD in geology from the University of Kentucky in 1977.

Arne C. Bathke is a Professor of statistics and Head of the Department of Matehmatics at Salzburg University, Salzburg, Austria, and Professor of statistics at the University of Kentucky. He received his Diploma and PhD in mathematics from Göttingen University, Göttingen, Germany.

\section{ACKNOWLEDGMENTS}

The work reported herein was supported by the University of Kentucky Center for Applied Energy Research and the National Institute for Hometown Security.

\section{REFERENCES}

1. Naaman, A. E.; Namur, G. G.; Alwan, J. M.; and Najm, H. S., "Fiber Pullout and Bond Slip. I: Analytical Study," Journal of Structural Engineering, ASCE, V. 117, No. 9, 1991, pp. 2769-2790. doi: 10.1061/ (ASCE)0733-9445(1991)117:9(2769)

2. ACI Committee 544, "Report on the Physical Properties and Durability of Fiber-Reinforced Concrete (ACI 544.5R-10)," American Concrete Institute, Farmington Hills, MI, 2010, 35 pp.

3. Lin, Z., and Li, V. C., "Crack Bridging in Fiber-Reinforced Cementitious Composites with Slip-Hardening Interfaces," Journal of the Mechanics and Physics of Solids, V. 45, No. 5, 1997, pp. 763-787. doi: 10.1016/S0022-5096(96)00095-6

4. Brown, R.; Shukla, A.; and Natarajan, K. R., "Fiber Reinforcement of Concrete Structures," Department of Chemical Engineering, University of Rhode Island, Kingston, RI, 2002, 51 pp.

5. Wang, Y.; Li, V. C.; and Backer, S., "Modelling of Fibre Pull-out from a Cement Matrix," International Journal of Cement Composites and Lightweight Concrete, V. 10, No. 3, 1988, pp. 143-149. doi: 10.1016/0262-5075(88)90002-4

6. Bentur, A.; Mindess, S.; and Vondran, G., "Bonding in Polypropylene Fibre Reinforced Concretes," International Journal of Cement Composites and Lightweight Concrete, V. 11, No. 3, 1989, pp. 153-158. doi: 10.1016/0262-5075(89)90087-0

7. Betterman, L. R.; Ouyang, C.; and Shah, S. P., "Fiber-Matrix Interaction in Microfiber-Reinforced Mortar," Advanced Cement Based Materials, V. 2, No. 2, 1995, pp. 53-61. doi: 10.1016/1065-7355(95)90025-X

8. Herrera-Franco, P. J., and Drzal, L. T., "Comparison of Methods for the Measurement of Fibre/Matrix Adhesion in Composites," Composites, V. 23, No. 1, 1992, pp. 2-27. doi: 10.1016/0010-4361(92)90282-Y

9. Mobasher, B., and Li, C. Y., "Effect of Interfacial Properties on the Crack Propagation in Cementitious Composites," Advanced Cement Based Materials, V. 4, No. 3-4, Oct.-Nov. 1996, pp. 93-105. doi: 10.1016/ S1065-7355(96)90078-4

10. Zucchini, A., and Hui, C. Y., "Detailed Analysis of the Fibre Pull-Out Test," Journal of Materials Science, V. 31, No. 21, 1996, pp. 5631-5641. doi: $10.1007 / \mathrm{BF} 01160808$

11. Wille, K., and Naaman,A. E. "Pullout Behavior of High-Strength Steel Fibers Embedded in Ultra-High-Performance Concrete," ACI Materials Journal, V. 109, No. 4, July-Aug. 2012, pp. 479-488.

12. Li, V. C., and Stang, H., "Interface Property Characterization and Strengthening Mechanisms in Fiber Reinforced Cement Based Composites," Advanced Cement Based Materials, V. 6, No. 1, 1997, pp. 1-20. doi: 10.1016/S1065-7355(97)90001-8

13. Kim, J., and Mai, Y., Engineered Interfaces in Fiber Reinforced Composites, Elsevier, New York, 1998, 416 pp.

14. Chan, Y.-W., and Chu, S.-H., "Effect of Silica Fume on Steel Fiber Bond Characteristics in Reactive Powder Concrete," Cement and Concrete Research, V. 34, No. 7, 2004, pp. 1167-1172. doi: 10.1016/j. cemconres.2003.12.023

15. Markovic, I., "High-Performance Hybrid-Fibre Concrete-Development and Utilisation," PhD dissertation, Delft University of Technology, Delft, the Netherlands, 2006, 228 pp.

16. Mehta, P. K., and Monteiro, P. J. M., Concrete: Microstructure, Properties and Materials, third edition, McGraw-Hill, New York, 2006, 659 pp.

17. Shah, S. P., "Do Fibers Increase the Tensile Strength of CementBased Matrixes?” ACI Materials Journal, V. 88, No. 6, Nov.-Dec. 1991, pp. 595-602.

18. Arjunan, P.; Silsbee, M. R.; and Roy, D. M., "Sulfoaluminate-belite Cement from Low-Calcium Fly Ash and Sulfur-Rich and Other Industrial By-Products," Cement and Concrete Research, V. 29, No. 8, 1999, pp. 1305-1311. doi: 10.1016/S0008-8846(99)00072-1 
19. Marroccoli, M.; Nobili, M.; Telesca, A.; and Valenti, G. L., "Early Hydration of Calcium Sulfoaluminate-Based Cements for Structural Applications," Sustainable Construction Technologies, Y.-M. Chun, P. Claisse, T. R. Naik, and E. Ganjian, eds., Taylor \& Francis Group, London, UK, 2007, pp. 389-395.

20. Ikeda, K., "Cements Along the Join C4A3S-C2S," International Congress on the Chemistry of Cement, V. 2, 1980.

21. ASTM C109/C109M-11, "Standard Test Method for Compressive Strength of Hydraulic Cement Mortars (Using 2-in. or [50-mm] Cube Specimens)," ASTM International, West Conshohocken, PA, 2011, 10 pp.

22. Arjunan, P.; Silsbee, M. R.; and Roy, D. M., "SulfoaluminateBelite Cement from Low-Calcium Fly Ash and Sulfur-Rich and Other Industrial By-Products," Cement and Concrete Research, V. 29, No. 8, 1999, pp. 1305-1311. doi: 10.1016/S0008-8846(99)00072-1

23. Taylor, H. F. W., Cement Chemistry, second edition, Thomas Telford, London, UK, 1997, 480 pp.

24. Brunner, E.; Dette, H.; and Munk, A., "Box-Type Approximations in Nonparametric Factorial Designs," Journal of the American Statistical Association, V. 92, No. 440, 1997, pp. 1494-1502. doi: 10.1080/01621459.1997.10473671

25. Redon, C.; Li, V. C.; Wu, C.; Hoshiro, H.; Saito, T.; and Ogawa, A., "Measuring and Modifying Interface Properties of PVA Fibers in ECC Matrix," Journal of Materials in Civil Engineering, ASCE, V. 13, No. 6, 2001, pp. 399-406. doi: 10.1061/(ASCE)0899-1561(2001)13:6(399)

26. Chu, T. J.; Robertson, R. E.; Najm, H.; and Naaman, A. E., "Effects of Poly(vinyl Alcohol) on Fiber Cement Interfaces. Part II: Microstructures," Advanced Cement Based Materials, V. 1, No. 3, 1994, pp. 122-130. doi: 10.1016/1065-7355(94)90043-4

27. Chu, T. J.; Robertson, R. E.; Najm, H.; and Naaman, A. E., "Effects of poly(vinyl alcohol) on fiber cement interfaces. Part II: Microstructures," Advanced Cement Based Materials, V. 1, No. 3, 1994, pp. 122-130. doi: 10.1016/1065-7355(94)90043-4

28. Hertzberg, R. W., Deformation and Fracture Mechanics of Engineering Materials, fourth edition, John Wiley \& Sons, Inc., Canada, 1996, 816 pp.
29. Brogren, C., and Karlsson, H. T., "Modeling the Absorption of $\mathrm{SO}_{2}$ in a Spray Scrubber Using the Penetration Theory," Chemical Engineering Science, V. 52, No. 18, 1997, pp. 3085-3099. doi: 10.1016/ S0009-2509(97)00126-7

30. Stengel, T., "Fibre Reinforced Civil Engineering Materials: A Model for Fibre Pull-Out Based on Tribological Mechanisms and Contact Mechanics," ECCM, IV European Conference on Computational Mechanics, Paris, France, 2010, 9 pp.

31. Neville, A. M., Properties of Concrete, fourth edition, Pearson Education Ltd., 1995, 844 pp.

32. Richardson, I. G., "The Nature of C-S-H in Hardened Cements," Cement and Concrete Research, V. 29, No. 8, 1999, pp. 1131-1147. doi: 10.1016/S0008-8846(99)00168-4

33. Horikoshi, T.; Ogawa, A.; Saito, T.; and Hoshiro, H., "Properties of Polyvinylalcohol Fiber as Reinforcing Materials for Cementitious Composites," International RILEM Workshop on High Performance Fiber Reinforced Cementitious Composites in Structural Applications, RILEM Publications SARL, Bagneux, France, 2006, pp. 145-153.

34. Bin, Y.; Mine, M.; Koganemaru, A.; Jiang, X.; and Matsuo, M., "Morphology and Mechanical and Rlectrical Properties of Oriented PVA-VGCF and PVA-MWNT Composites," Polymer, V. 47, No. 4, 2006, pp. 1308-1317. doi: 10.1016/j.polymer.2005.12.032

35. Cadek, M.; Coleman, J. N.; Barron, V.; Hedicke, K.; and Blau, W. J., "Morphological and Mechanical Properties of Carbon-Nanotube-Reinforced Semicrystalline and Amorphous Polymer Composites," Applied Physics Letters, V. 81, No. 27, 2002, pp. 5123-5125. doi: 10.1063/1.1533118

36. Naebe, M.; Lin, T.; Staiger, M. P.; Dai, L.; and Wang, X., "Electrospun Single-Walled Carbon Nanotube/Polyvinyl Alcohol Composite Nanofibers: Structure-Property Relationships," Nanotechnology, V. 19, No. 30, 2008, p. 8 doi: 10.1088/0957-4484/19/30/305702

37. Chanvillard, G., and Aïtcin, P.-C., "Pull-out Behavior of Corrugated Steel Fibers: Qualitative and Statistical Analysis," Advanced Cement Based Materials, V. 4, No. 1, 1996, pp. 28-41.

38. Box, G. E. P., and Cox, D. R., "An Analysis of Transformations," Journal of the Royal Statistical Society. Series B. Methodological, V. 26, No. 2, 1964, pp. 211-252. 